\title{
Cellular Therapies
}

\section{HIGH THROUGHPUT SCREENING OF HPV-ANTIGEN PEPTIDES AND EXPANSION OF TUMOR-SPECIFIC T CELLS FOR ADOPTIVE CELL THERAPY OF HPV- ASSOCIATED MALIGNANCIES}

David Langan*, Jourdain Lemaster, Lauren Suarez, Pratima Kunwar, Sojung Kim, Mathias Oelke. Neximmune, Gaithersburg, MD, USA

Background NexImmune is developing highly differentiated immunotherapies to target, activate and expand tumor antigen-specific $\mathrm{T}$ cells using the proprietary Artificial Immune Modulation $\left(\mathrm{AIM}^{\mathrm{TM}}\right.$ ) nanotechnology platform. The AIM nanoparticle (AIM-np) technology functions as synthetic dendritic cells capable of directing a specific $\mathrm{T}$ cell-mediated immune response. By mimicking natural $\mathrm{T}$ cell biology, NexImmune's cellular therapy product candidates (AIM ACT) are designed to combine the attributes of cellular precision, potency, and persistence with reduced potential for undesired toxicities. Human papilloma virus (HPV) is responsible for $>45,000$ cancers yearly in the United States, according to the CDC. From 2013-2017 an estimate 79\% of cervical, vulva, penis, vaginal, anus, and oropharyngeal cancers were attributed to HPV and of these about $80 \%$ were associated with high-risk HPV types 16 and 18. Although multivalent vaccines against high-risk HPV infections exist, significant clinical challenges remain. A limited vaccination rate means many remain vulnerable and vaccination does not treat pre-existing HPV infections or malignancies.

Methods Therefore, NexImmune is employing its AIM-np technology to generate an adoptive cell therapy (ACT) using its proprietary enrichment and expansion $(\mathrm{E}+\mathrm{E})$ ex vivo process to expand clinically relevant numbers of $\mathrm{CD} 8+\mathrm{T}$ cells that recognize the HPV16 and HPV18 oncogenic antigens (i. e., E6 and E7) expressed by malignant cells of head and neck, cervical, and anal cancers. Using the Immune Epitope Database and Analysis Resource (IEDB), 44 HLA-A2 restricted peptides were identified as potential immunogenic targets for preclinical screening. Using PBMCs from healthy donorderived apheresis material, different combinations of these peptides were used in the $\mathrm{E}+\mathrm{E}$ process to expand HPV-cancer specific CD8 + T cells.

Results After multiple E+E experiments were concluded, 5 peptides were identified that consistently elicited the strongest $\mathrm{T}$ cell responses. Furthermore, these CD $8+\mathrm{T}$ cells were predominantly from the central memory (CD62L+CD45RA-) and effector memory (CD62L-CD45RA-) phenotype (sum total $82.18 \pm 8.29$ [Mean \pm SEM]) suggesting their in vivo functionality and persistence will combine anti-tumor activity with long-term immunologic memory.

Conclusions A similar E+E screening is being conducted with PBMCs isolated from $\mathrm{HPV}+$ cancer patients. A comparison of the CD8 + $\mathrm{T}$ cell responses from healthy donor and cancer patient cells will provide critical preclinical data to support a planned FIH trial for HPV-associated malignancies. The current study demonstrates the ability for high-throughput peptide screening to identify clinically relevant peptide cocktails capable of expanding multi-antigen tumor-specific $\mathrm{CD} 8+\mathrm{T}$ cell populations within 2 weeks. 